\title{
The Right to Carbon Emission: A New Right to Development ${ }^{*}$
}

\author{
-A Chinese Perspective
}

\author{
Zewei Yang \\ Luojia Distinguished Professor, Wuhan University, Wuhan, China \\ Email: yangzewei@hotmail.com
}

Received April 11, 2012; revised May 9, 2012; accepted May 20, 2012

\begin{abstract}
For the past few years, the international community has regarded the right to carbon emission as a new right to development. The legal basis of this mainly includes "the United Nations Framework Convention on Climate Change", "the Kyoto Protocol" as well as the sustainable development principle, the principle of common but differentiated responsibilities and the principle of fairness and justice, etc. The distribution of the right to carbon emission of the post-Kyoto age should consider the need of development, population, historical responsibility, the principle of fairness and justice and other factors. As a dominant country of greenhouse gas emission, on the premise of sticking to "the principle of common but differentiated responsibilities", China should achieve the transformation from the "difference principle" to "common responsibilities" progressively. Meanwhile, in strengthening coordination with developing countries, China should appropriately support the requests of the Alliance of Small Island States and the least developed countries and attach importance to the issue of the right to development in the distribution of the right to carbon emission.
\end{abstract}

Keywords: Climate Change; The Right to Carbon Emission; The Right to Development

\section{Introduction}

In recent years, climate change issues have become the focus of world opinion. In the post-Kyoto age (20122020), issues of the distribution of the right to carbon emission have become one of the core problems of climate talks. China, as the biggest developing country and a dominant country of greenhouse gas emission in the world, the distribution of the right to carbon emission not only concerns the scope for development of China's future but also touches on the fundamental interests of the majority of developing countries. Therefore, there is no doubt that it has important practical significance to research on the distribution of the right to carbon emission of the post-Kyoto age from the perspective of the right to development.

\section{Characteristic of the Right to Carbon Emission}

\subsection{Climate Change and the Birth of the Right to Carbon Emission}

The right to carbon emission, which refers to the right "This article is sponsored by the Great Project of the China National
Social Science Fund on "A Study of New Energy Policies and Laws in
Developed Countries and the Choice of China's Strategies" (Project Grant No. 09\&ZD048). that emits greenhouse gas to the atmosphere which was given by nature or law in order to survive and develop, the essence of the right is the right to use a certain amount of environmental resources which was obtained by the subject of right. The birth of the right to carbon emission closely interrelated with human beings' concern about climate change issues.

Early in the 1970s, scientists had put forward climate warming as a global environmental issue. In 1988 the World Meteorological Organization and the United Nations Environment Program established "the Intergovernmental Panel on Climate Change” (IPCC). In December of the same year, the United Nations General Assembly adopted the Resolution 43/53 which is on protecting climate, declaring climate change is "a common concern of mankind" [1]. In 1992, the Rio Conference on Environment and Development passed "the United Nations Framework Convention on Climate Change" ("the Convention on Climate Change"), which prescribed that developed countries should combat climate change and its adverse effects first, they should then cut their greenhouse gas emissions to 1990's levels at the end of 20th century. In 1997, the third meeting of the contracting parties passed "the Kyoto Protocol", which requires developed countries should reduce $5 \%$ of their greenhouse gas emissions on average to the levels of the 1990's from 
2008 to 2012: the European Union would cut 8\%, United States of America cut 7\%, and Japan and Canada cut 6\%. Due to the target commitment period of "the Kyoto Protocol" only to 2012, therefore, the question of how to distribute the right to carbon emission after 2012 has become the focus of debate of the international community [2].

\subsection{Subject of the Right to Carbon Emission}

Concerning the right to carbon emission, there are the following three types:

\subsubsection{Nation}

Both "the Convention on Climate Change" and "the Kyoto Protocol" are from the perspective of the international fair to take the country as a unit to define a country's right to carbon emission: they distinguished developed countries' and developing countries' "National Total Carbon Emissions" indexes in different period in the national responsibility for carbon emission reduction. The national carbon emission right which takes the state as subject, though it notes the fairness in the national level, however, it neglects unfairness between people [3].

\subsubsection{Group}

The group carbon emission right which takes the group as the main body type, mainly refers to the right that all sorts of enterprises or business institutions obtained emission indexes and then emit greenhouse gas to the atmosphere that meet the regulations prescribed by law. The group carbon emission right has transferability, which is the basis of the establishment of an international greenhouse gas emissions trading system.

\subsubsection{Natural Person}

The individual carbon emission right which takes natural person as the main body type, refers to each individual wherever he or she is, and has the inherent right to emit greenhouse gas to the atmosphere for their survival and development needs. The distribution of the right to carbon emission of the post-Kyoto age should pay more attention to the individual carbon emission right issues.

\subsection{The Right to Carbon Emission Is a New Right to Development ${ }^{1}$}

"Climate change is a major global issue of common con-

\footnotetext{
${ }^{1}$ In 1986, the General Assembly Resolution 41/128 passed "Declaration on the Right to Development" pointed out, "the right to development is an inalienable human right by virtue of which every human person and all peoples are entitled to participate in, contribute to, and enjoy economic, social, cultural and political development, in which all human rights and fundamental freedoms can be fully realized"; and recognizing that "development is a comprehensive economic, social, cultural and political process, which aims at the constant improvement of the well-being of the entire population and of all individuals on the basis of their active, free and meaningful participation in development and in the fair distribution of benefits resulting there from”.
}

cern to the international community. It is an issue involving both environment and development, but it is ultimately an issue of development" [4]. Therefore, it has become the consensus of the international community to link the climate change issues to sustainable development. Based on this, to regard the right to carbon emission as a new right to development has gradually been recognized by the international community. For example, USA schoolars Eric A. Posner, Cass R. Sunstein and Bryan A. Green have recognized that the right to carbon emission is a new right to development [5]. Kenyan Nairobi University Professor Albert Mumma thinks that "the emission entitlements, in effect, are a proxy for the right to develop and meet the needs of one's nation and the well-being of its people" [6]. Based on the sustainable humanity development theory, A. Sen proposed that the fundamental purpose of development is to expand the range of human beings' choices and achieve the overall development of human beings. [7] Besides, Bryan A. Green further pointed out that "the Principle of Common but Differentiated Responsibilities" should also include "the responsible development” [8] of developing countries.

In fact, as a new right to development, there are two layers of meaning of the right to carbon emission: firstly, the right to carbon emission is "a natural right, a birthright of every person, a right which has nothing to do with the social status and personal wealth" [9]. Secondly, "the allocation of emission rights represent a right to utilize Earth's resources for development” [6], this is especially true for developing countries.

\section{Legal Basis of the Right to Carbon Emission as a Right to Development}

\subsection{Foundation of Law of the Right to Carbon Emission}

In 1990 the United Nations General Assembly started intergovernmental negotiation in order to conclude a convention to prevent climate change. Since then, the international community has successively formulated "the Convention on Climate Change", "the Kyoto Protocol”, "the Bonn Agreement”, "the Buenos Aires Action Plan”, "the Malakeshen Agreement”, "the Delhi Declaration” and "the Bali Road Map" and other series of important documents. They have played a key role in the process of strengthening the global consensus and mitigating global climate change, [10] and laid a solid legal basis for the right to carbon emission. Among them, the most important are "the Convention on Climate Change" and "the Kyoto Protocol”.

\subsection{1. "The Convention on Climate Change"}

"The Convention on Climate Change" affirmed that, "responses to climate change should be coordinated with 
social and economic development in an integrated manner with a view to avoiding adverse impacts on the latter, taking into full account the legitimate priority needs of developing countries for the achievement of sustained economic growth and the eradication of poverty. Recognizing that all countries, especially developing countries, need access to resources required to achieve sustainable social and economic development". "The Parties have a right to, and should, promote sustainable development. Policies and measures to protect the climate system against human-induced change should be appropriate for the specific conditions of each Party and should be integrated with national development programmes, taking into account that economic development is essential for adopting measures to address climate change.”

\subsection{2. "The Kyoto Protocol”}

“The Kyoto Protocol” also clearly links up quantified emission limitation and emission reduction commitments with the efforts of promoting sustainable development. For instance, the first paragraph of Article 2 prescribes, "Each Party included in Annex I, in achieving its quantified emission limitation and reduction commitments under Article 3, in order to promote sustainable development, shall implement and/or further elaborate policies and measures in accordance with its national circumstances". Article 3 points out, "the Parties included in Annex I shall, individually or jointly, ensure that their aggregate anthropogenic carbon dioxide equivalent emissions of the greenhouse gases listed in Annex A do not exceed their assigned amounts, calculated pursuant to their quantified emission limitation and reduction commitments inscribed in Annex B and in accordance with the provisions of this Article, with a view to reducing their overall emissions of such gases by at least 5 percent below 1990 levels in the commitment period 2008 to 2012."

In addition, the Bali Act Plan also mentioned the sustainable development principle and proposed the task of consultation to the post-Kyoto system [11].

\subsection{Theoretical Basis of the Right to Carbon Emission}

The sustainable development principle, the principle of common but differentiated responsibilities and the principle of fairness and justice provided theoretical basis for the right to carbon emission as a right to development.

\subsubsection{The Sustainable Development Principle}

Judge Weeramantry of the International Court of Justice pointed out that the sustainable development principle is a constituent part of modern international law. This is not only because of inevitable existing logic, but also that the international society has recognized the principle universally and widely [12]. According to the Brundtland Report, "the sustainable development principle is the development that satisfies the needs of the present-day men as well as without doing harm to meet the needs of future generations" [13]. There is no doubt that "the Convention on Climate Change" is one of the main documents in the field of sustainable development. For example, the forth paragraph of Article 3 of the convention announced, "the Parties have a right to, and should, promote sustainable development”. The seventh paragraph of Article 4 of the convention points out, "the extent to which developing country Parties will effectively implement their commitments under the Convention will depend on the effective implementation by developed country Parties of their commitments under the Convention related to financial resources and transfer of technology and will take fully into account that economic and social development and poverty eradication are the first and overriding priorities of the developing country Parties.” These provisions of the convention reflect the right to development and the obligation of changing the mode of unsustainable production and consumption. The first paragraph of Article 2 of "the Kyoto Protocol" also links up emission reduction commitment to sustainable development.

From August to September 2002, the World Summit on Sustainable Development was held in Johannesburg, South Africa and passed "the Implementation Plan for Sustainable Development” [14]. Thereafter, under the framework of sustainable development, considering mitigating and adapting climate change issues has become a new idea in climate change talks. [15] In October of the same year, the eighth meeting of the parties of Climate Change Convention passed "the Delhi Declaration". "It is the first time in the international document that clearly proposed we should combat climate change issues under the framework of sustainable development" [16].

It is noteworthy that the Article 2 of 2009 "the Copenhagen Accord" also prescribes, "we should cooperate in achieving the peaking of global and national emissions as soon as possible, recognizing that the time frame for peaking will be longer in developing countries and bearing in mind that social and economic development and poverty eradication are the first and overriding priorities of developing countries and that a low-emission development strategy is indispensable to sustainable development."

\subsubsection{The Principle of Common but Differentiated Responsibilities}

"The Principle of Common but Differentiated Responsibilities" refers to, on the basis of the integrity of the earth's ecosystem, each country has the common responsibilities to protect global environment, but there are big 
differences among them of their specific responsibilities due to their different capabilities. In 1992, the United Nations Conference on Environment and Development established "the Principle of Common but Differentiated Responsibilities". Principle 7 of "Rio Declaration on Environment and Development" announced "every country has common but differentiated responsibilities". "The Convention on Climate Change" is the first international environmental legal document that clearly used the wording of "the Common but Differentiated Responsibilities" [17]. In the preface of the convention, it stressed "calls for the widest possible cooperation by all countries and their participation in an effective and appropriate international response, in accordance with their common but differentiated responsibilities and respective capabilities and their social and economic conditions.” Besides, Article 3 "principles", Article 4 "commitments" of "the Convention on Climate Change" also reflects the requirements of "the Principle of Common but Differentiated Responsibilities". And "the Kyoto Protocol” further implementing "the Principle of Common but Differentiated Responsibilities" in the way of developed countries quantified emission reduction and put developing countries under no mandatory emission reduction obligation. It is obvious that "the Principle of Common but Differentiated Responsibilities" clearly acknowledges, both in history and at present, that most of the global greenhouse gas emission was from developed countries. The per capita emission of developing countries is still relatively low. In order to meet social and developmental needs, the proportion of developing countries will increase in global emissions.

Though "the Principle of Common but Differentiated Responsibilities" actually has not been regarded as binding international law, yet it has become the foundation of the establishment of responsibility sharing arrangements in international environmental treaties. Therefore, developed countries should hold more responsibility for controlling greenhouse gas emissions [18]. In the distribution of the right to carbon emission of the post-Kyoto age, the cornerstone status of "the Principle of Common but Differentiated Responsibilities” was still unshakeable in the view of the economic and social developmental needs of developing countries. As Premier Wen Jiabao stressed in the Copenhagen Climate Change Conference in December 2009, “'the Principle of Common but Differentiated Responsibilities' is the core and cornerstone for various countries cooperation in dealing with climate change, we should always adhere to it” [19].

\subsubsection{The Principle of Fairness and Justice}

Climate change is not only an ecological question, but also a fair question [20]. If we can not solve the interaction between climate change and justice, we can never combat climate change successfully [21]. Therefore, the principle of fairness and justice has become one of the theoretical bases of the right to carbon emission as a right to development.

Firstly, the United Nations Charter solemnly declared in the preface, "faith in - the equal rights — of nations large and small", and established the purpose "to develop friendly relations among nations based on respect for the principle of equal rights and self-determination of peoples" in Article 1. Secondly, "the Universal Declaration of Human Rights" respectively prescribed in article 1and Article 2, "all human beings are born free and equal in dignity and rights," "everyone is entitled to all the rights and freedoms set forth in this Declaration, without distinction of any kind, such as race, colour, sex, language, religion, political or other opinion, national or social origin, property, birth or other status." Lastly, according to Rawls" "Two Principles of Justice" theory, to the similar freedom system of other people's most extensive basic freedom system, everyone should have an equal right; social and economic inequality should be arranged like this and be reasonably expected to suit everyone's interests, and open to all in accordance with status and post. [22] The former is "the Principle of Equality and Freedom", while the latter is "the Principle of Differentiated and the Principle of Fair Equality of Opportunity".

Therefore, we should adhere to "the Principle of Fairness and Justice" in considering the question of the distribution of the right to carbon emission of all countries. As Rawls pointed out, all the social values, freedom and opportunity; income and wealth; the basis of self-esteem, all shall be equally distributed unless an inequality distribution of a value or all the values suits everyone's interests" [23].

\section{The Distribution of the Right to Carbon Emission as the Right to Development}

\subsection{The Existing Solutions of the Distribution of the Right to Carbon Emission}

There have been more than 20 solutions for the distribution of the right to carbon emission in the current international community, among them are the following: $[24,25]$.

\subsubsection{Contraction and Convergence}

In 1990, the British Global Commons Institute initiative "Contraction and Convergence", developed countries gradually reduce to per capita from the present high emission while developing countries gradually increase to the global average from the current low level emission so that the global per capita emission will converge in the target year and ultimately achieve the goal of concentration of global stability [26]. Some scholars proposed the distributing method of "the Two Convergences" 
based on this, namely that the per capita emission of every country will converge in 2100, and the accumulated per capita emission will converge from 1990 to the convergence year (2100) [27].

\subsubsection{Brazil Proposal}

In 1997, the Brazilian government submitted "on the proposal main point of 'the Protocol to the Climate Change Convention'” to the "Berlin authorized special panel”, which was based on Annex I a nation's relative historical contributions to global warming to distinguish and divide emission reduction responsibility and goal in the first commitment period of "the Kyoto Protocol", and that earlier industrialized countries need to bear greater emission reduction obligation. The Brazil Proposal aroused extensive concern in the scientific community as soon as it appeared, and some new solutions of distribution were derived from it [1].

\subsubsection{Multi-Sector Convergence Approach of Burden Sharing}

In 2001, the Energy Research Centre of the Netherlands (NCN) and the Centre for International Climate and Environmental Research-Oslo (CICERO) cooperatively developed a more complex global "Multi-sector Convergence Approach of Burden Sharing" on the basis of "Triptych". It mainly divided the national economy of all the countries into seven departments including power generation, industry, civil, transportation, services, agriculture, waste and other departments. It determined the department emission limitations according to the method of per capita emission convergences of every department and every country [28].

\subsubsection{Framework to Assess International Regimes for Burden Sharing (FAIR)}

In 2001, the National Institute of Public Health and the Environment (RIVM) of the Netherlands developed the "Framework to Assess International Regimes for Burden Sharing" (FAIR), which extended the sharing method based on historical responsibility to developing countries. Their multi-stage participation method divided the emission reduction obligations assumed by developing countries into the following four stages: standard emission scenario stage, carbon emission intensity declining stage, stabilized emission stage and emission reduction stage [29].

\subsubsection{The Carbon Emission Solution Which Meets the Basic Needs of Humanity Development}

The solution divided carbon emission into the carbon emission for basic needs and extravagant and wasteful carbon emission. It stressed that per capita emission is one of human beings' basic developmental rights, and the reduction solution must be able to guarantee international fair and interpersonal justice. The specific goal of emission reduction should be with the humanity development goal of the United Nations [30].

As seen from the above, the above solutions were orientated for different interests and are complementary to each other. But they are either avoiding historical responsibility or ignoring the right to development or other factors, therefore, they are not satisfactory solutions. In other words, a distribution system of emission right which is unified and accepted by all the countries has not been established.

\subsection{Factors Affecting the Distribution of the Right to Carbon Emission}

In view of the defects of the existing distributing solutions of the right to carbon emission of international community, we think we should take the following factors into consideration in formulating a distributing solution of the right to carbon emission:

\subsubsection{The Need of Development}

"The right to development is the important foundation of the realization of other human rights particularly economic and social rights" [31]. "Because without a considerable degree of development, a society cannot provide conditions or give security for the members' realizing their social and economic rights; namely providing active public services for the members and guaranteeing their reaching the minimum living standards” [32]. Therefore, in the distribution of the right to carbon emission, on the one hand we should meet the basic survival needs of developing countries and guarantee their citizens' basic energy needs and material needs; ${ }^{2}$ on the other hand, because "the least developed countries are the biggest victims of climate change until now" [6], in determining the emission reduction of the post-Kyoto age we should take intra-generational equity as the foundation and guarantee the sustainable development need of developing countries. Only by sustainable development, improving the level of economic development and their own ability can developing countries combat climate change effectively.

\subsubsection{Population}

Citizens of each country have the same right to climate, environment and other global public products, each country has no right in per capita emission aspects to be higher than any other country. Therefore, the distribution of the right to emission considering population, which

\footnotetext{
${ }^{2}$ Nowadays some 1.5 to 2 billion people in the world have no access to electricity. They have no light at night (unless they burn kerosene or candles), no refrigeration, no radio. They have no cars or trucks. They burn (unsustainably) biomass to cook [6].
} 
means admitting the right to emission is the right to subsistence and development, is an integral part of basic human rights from another perspective, and it also demonstrates the equal rights of the human survival, development and utilization of natural resources. In addition, the principle of the right of per capita emission is in line with ethics and justice, because according to the statistics of the International Energy Agency, in 2004, the highest carbon dioxide emission per capita is the United States of America 19.73 tons, followed by Russia 10.63 tons, Germany 10.29 tons, Japan 9.52 tons, United Kingdom 8.98 tons, France 6.22 tons, but China has only 3.66 tons [6].

\subsubsection{Historical Responsibility}

"The Convention on Climate Change" clearly pointed out in the preface "noting that the largest share of historical and current global emissions of greenhouse gases has originated in developed countries". Developed countries' historical accumulation emissions total quantity and the per capita historical accumulation emissions are much higher than that of developing countries. According to the statistics of the United Nations Development Programme, $70 \%$ of the global carbon dioxide was from the United States of America, Russia, Germany, United Kingdom, France, Japan, Canada and Poland [33]. But the World Resources Institute data indicates the historical accumulation emission most since 1850 to 2003, is the United States of America, which accounts for 29\%; next is European Union, accounts for $26 \%$. Therefore, developed countries should take "the Historical Responsibility", [34] and be responsible for the consequences of their actions and pay for their actions. Taking this into consideration, in the distribution of the right to emission of the post-Kyoto age, developed countries should consider their consumed emission space in advance and correspondingly reduce their future emission amount and achieve "the Corrective Justice” [35].

\subsubsection{The Principle of Fairness and Justice}

The first paragraph of Article 3 of "the Convention on Climate Change" prescribes, "the Parties should protect the climate system for the benefit of present and future generations of humankind, on the basis of equity and in accordance with their common but differentiated responsibilities and respective capabilities". Therefore, the distribution of the index of the right to carbon emission must follow the principle of fairness and justice. On the one hand, we need to consider the fairness of national level and ensure the same emission right of developing countries and developed countries. As some scholars have said, "all the appeals for effectively protecting climate will be in vain if we can not achieve greater equity between North and South" [36]. On the other hand, we should seek "Intra-generational Equity" [21] in order to ensure the basic rights that should be enjoyed by all the people, especially the vulnerable groups that are in unfavourable positions in the society, and achieve human beings' enjoyment of equal rights to subsistence and equal right to development.

\subsubsection{Other Factors}

In distributing the right to carbon emission in the postKyoto age, we should also consider geographical conditions, resources endowments, energy efficiency [6], industrial structure, technological level [37], human development index [8] and other factors. These factors can all play certain corrective roles in distribution of the indexes of the right to carbon emission.

\section{China's Policy: Some Suggestions}

Concerning the distribution of the right to carbon emission issues: on the surface it is an argument about combating climate change and protecting the global environment between developing countries and developed countries, but in essence it is the contest about energy security and economic development strategy in the 21st century of each major country and interest group, and its effects may involve several generations. As a dominant country of greenhouse gas emission, it seems especially pressing for China to seek for a policy to defuse the great pressure of climate change issues.

\subsection{The Transformation from the "Difference Principle" to "Common Responsibilities"}

As we has mentioned before, "the Principle of Common but Differentiated Responsibilities" is the foundation for various countries cooperation in combating climate change, but the principle is facing serious challenges today. On the one hand, "the Principle of Common but Differentiated Responsibilities” has fully suffered from criticism in recent years and has the risk of being abandoned. For example, the United States of America has always emphasized that because of the absence in setting binding emission reduction obligations to China and other developing countries, it refused to ratify "the Kyoto Protocol” [34]. But some European and American scholars also believe that "developing countries have every reason to enjoy differential treatment in the international treaties that deal with global environmental problems. However, 'the Kyoto Protocol' seems went so far along the direction of differentiated responsibility that deviated from the orbit of common responsibility. The principle should not be interpreted as to the matters of common concerns that need the differentiated responsibility. It seems fair to exclude certain countries while actually affecting the realization of the entire target” [38]. On the 
other hand, the change of the global greenhouse gas emission pattern also led to "the Principle of Common but Differentiated Responsibilities" is being weakened. In 1997 when "the Kyoto Protocol" was formulated, the proportion of carbon emissions of developing countries including China was not high. But their carbon emissions are increasing rapidly with the rapid economic development of China, India, Brazil and other developing countries. If binding emission reduction obligations have not been imposed on the main carbon dioxide emissions developing countries, then "the Principle of Common but Differentiated Responsibilities" will go beyond the restrictions of the objects and purposes of "the Convention on Climate Change" [39]. So "the 'Responsibility' referred to in 'the Principle of Common but Differentiated Responsibilities' are common to everyone, not just the developed world" [16].

Therefore, on the premise of sticking to the "principle of common but differentiated responsibilities", China should gradually take more emission reduction responsibility together with developing countries particularly big developing countries and realize the transformation from the "Difference Principle" to "Common Responsibilities" progressively. It should be an important tendency for future development. On the eve of the Copenhagen Conference, the Chinese government initially made emission reduction commitments, and this is to some extent a reflection of this trend.

\subsection{Emphasize the Transfer Emission Question Caused by Trade and Investment}

The transfer emission question resulting from trade and investment has increasingly attracted attention around the world in recent years. In 2008, in the United Nations Climate Change Bonn Conference, an Indian scholar proposed that we should let developed countries be responsible for the additional emissions to developing countries resulting from foreign direct investment, thus expanding more carbon emission space for their own developmental needs for developing countries [8]. In fact, due to the impact of international division of labour and trade, developed countries have taken advantage of using China's cheap production costs and transferred the low added value, high energy consumption industries to China, which made China play the role of "World Factory" in the global economic system. This kind of world economic and trade pattern made the consumption originated from Europe-American countries accounted for about $20 \%$ of China's greenhouse gas emissions total amount. Therefore, this factor should be considered in the distribution of the right to carbon emission in the post-Kyoto age. Only in this way can we truly reflect the principle of fairness and justice.

\subsection{The Differences between the Interest Demands Led to the Differentiation of Developing Countries, thus We Should Seek for New Alliances}

There have been various national groups in today's global climate political arena, their complex internal relations have gone completely beyond the simple dichotomy of the so-called "North-South Gap" or "Two Worlds” since 1960s. And, there are also big differences among the interest demands of the internal different groups of developing countries. For example, the Alliance of Small Island States $^{3}$ most worried about sea level rise, strongly demanded strictly implementing the emission reduction resolutions. While the least developed countries are particularly concerned about future financial assistance instead of the distribution of the right to emission. But China, India, Brazil, South Africa and that is the "Basic Four Countries"4 opposed setting binding emission reduction obligations on them, for their economic and social development was still in the process of industrialization and modernization, and in some areas their population was still in poverty. At the same time, China's developing country status is increasingly being questioned. Some European and American scholars believe that if we still regard China as a developing country, not only we are unable to create an effective institutional framework to combat climate change, but also it is unfair to the whole world, therefore we must differentiate it ${ }^{5}$.

In fact, in the Copenhagen Conference, around the distribution of the right to carbon emission of the postKyoto age and technology transfer and other questions, the two sides were traditional powers represented by America, European countries and emerging powers represented by China and India. Therefore, in future negotiations on climate change, the Chinese government should note the fact that developing countries have been differentiated in addition to continuing to participate in the negotiations by developing country status. Meanwhile, in strengthening coordination with developing countries, China should appropriately support the requests of the Alliance of Small Island States and the least developing countries in order to deal with the pressures and challenges of developed countries.

\footnotetext{
${ }^{3}$ The Alliance of Small Island States was established in 1990 and composed of 43 members and observers, including Singapore and small island states from Africa, Caribbean Sea, Indian Ocean, Mediterranean Sea, Pacific Ocean and South China Sea. The purpose of the alliance is to consolidate the voices of vulnerable small islands and low-lying coastal states to address global climate change and the similar developmental challenges and environmental concerns within the United Nations system.

4“"Basic Four Countries” refers to China, India, Brazil and South Africa the name comes from the acronym of the English first letters of the four countries, "basic" refers to China, India, Brazil and South Africa.

${ }^{5}$ They regard China, India etc. as the Emerging Economies or the Fast-growing Developing Countries [2].
} 


\subsection{Attaching Importance to the Issues of the Right to Development in the Distribution of the Right to Carbon Emission}

“The primary task for China's participating in international activities in the field of climate change and carrying out agreements and negotiating is to strive for the proper right to development for the realization of industrialization and modernization as well as sustainable development, namely strive for necessary emission space for future development” [3]. Therefore, the Chinese government should adhere to the sustainable development strategy and maintain the basic framework of "the United Nations Framework Convention on Climate Change" and "the Kyoto Protocol". On the one hand, China acknowledged that emission reduction is the trend of economic and social development, and is the inevitable progress of human civilization; on the other hand, resolutely safeguarding the developmental interests of China as a developing country, emphasizing that economic development and poverty eradication are the overriding priority tasks of developing countries. And China should persist in giving more rights to carbon emission to developing countries, the vulnerable groups of climate change and the poor based on the realization of the right to development [2].

In conclusion, the distribution of the right to carbon emission is closely related to various countries' future developmental space. Therefore, research on the distribution of the right to carbon emission from the perspective of the right to development, or the concept of regarding the right to carbon emission as a new right to development could provide more ideas and creativity for the designing of international climate mechanism of the postKyoto age.

\section{REFERENCES}

[1] L. Han, "On Legal Issues of Emission Rights Trade of International Greenhouse Gas,” China Legal Publishing House, Beijing, 2009, p. 29.

[2] A. M. Halvorssen, "Common, but Differentiated Commitments in the Future Climate Change Regime-Amending the Kyoto Protocol to Include Annex $\mathrm{C}$ and the Annex $\mathrm{C}$ Mitigation Fund,” Colorado Journal of International Environmental Law \& Policy, Vol. 18, No. 2, 2007, pp. 247266.

[3] J. M. Yang, "Global Climate Change Diplomacy and China's Policy," Shi Shi Publishing House, Shanghai, 2009, pp. 243-245.

[4] The National Development and Reform Commission, “China's National Climate Change Programme,” The National Development and Reform Commission, Beijing, 2007.

[5] E. A. Posner and C. R. Sunstein, "Climate Change Justice," Georgetown Law Journal, Vol. 96, No. 4, 2007-2008, p.
1603.

[6] A. Mumma and D. Hodas, "Designing A Global PostKyoto Climate Change Protocol that Advances Human Development,” Georgetown International Environmental Law Review, Vol. 20, No. 4, 2007-2008, p. 639.

[7] A. Sen, "Development as Freedom,” Oxford University Press, Oxford, 1999, p. 18.

[8] B. A. Green, "Lessons from the Montreal Protocol: Guidance for the Next International Climate Change Agreement," Environmental Law, Vol. 39, No. 2, 2009, p. 281.

[9] Jan Hancock, “Environmental Human Rights,” Ashgate Publishing, Farnham, 2003, pp. 59-63.

[10] The Office of China National Climate Change Programme Coordination Group and the Centre for China's 21st Century Agenda Management, "Global Climate Change: A Challenge for Humankind,” The Commercial Press, Beijing, 2004, p. 2.

[11] United Nations Framework Convention on Climate Change, "Report of the Conference of the Parties on Its Thirteenth Session,” The Conference of the Parties, Bali, 3-15 December 2007.

[12] N. Schrijver, "The Evolution of Sustainable Development in International Law: Inception, Meaning and Status," Recueil des Cours (Hague Academy of International Law), Vol. 329, No. 1, 2007, p. 217.

[13] S. Q. Cai., et al., "Sustainable Development and Legal System of Environmental Resources," China Legal Publishing House, Beijing, 2003, pp. 14-15.

[14] United Nations, "Report of the World Summit on Sustainable Development," World Summit on Sustainable Development, Johannesburg, 26 August-4 September 2002. http://www.unctad.org/en/docs/aconf199d20\&cl_en.pdf

[15] A. M. Halvorssen, "Global Response to Climate ChangeFrom Stockholm to Copenhagen,” Denver University Law Review, Vol. 85, No. 4, 2007-2008, p. 846.

[16] G. Y. Zhuang and Y. Chen, "International Climate Regime and China,” World Affairs Press, Beijing, 2005, p. 251.

[17] X. Yang, "On the United Nations Framework Convention on Climate Change-International Law and Comparative Law Perspective,” China Legal Publishing House, Beijing, 2007, p. 133.

[18] C. D. Stone, "Common but Differentiated Responsibilities in International Law," American Journal of International Law, Vol. 98, No. 2, 2004, pp. 276-301. doi: $10.2307 / 3176729$

[19] The United Nations Climate Change Conference, "Chinese Premier Wen Jiabao Speaks at the Leaders’ Meeting of the United Nations Climate Change Conference in Copenhagen," Copenhagen, 18 December 2009. http://www.gov.cn/ldhd/2009-12/19/content_1491149.htm

[20] E. Vermeersch, "Reading the Kyoto Protocol: Ethical Aspects of the Convention on Climate Change," Eburon Uitgeverij B.V., Delft, 2005, p. 84.

[21] S. Johnson, "Climate Change and Global Justice: Crafting Fair Solutions for Nations and Peoples," Harvard Environmental Law Review, Vol. 33, No. 2, 2009, pp. 297-301.

[22] J. Rawls, “A Theory of Justice,” Harvard University Press, 
Cambridge, 1971, p. 55.

[23] A. Torvanger, et al., "A Survey of Differentiation Methods for National Greenhouse Gas Reduction Targets, Centre for International Climate and Environmental Research-Oslo Report,” 1999, p. 5.

[24] D. Bodansky, "International Climate Efforts Beyond 2012: A Survey of Approaches," The Pew Center on Global Climate Change, Washington DC, 2004, pp. 1-35.

[25] http://www.globalcommons.org

[26] W. Y. Chen, et al., "The Distributing Method of 'the Two Convergences' of Global Carbon Emission Rights,” Tsinghua University Journal, No. 6, 2005, pp. 850-853.

[27] The Energy Institute of the National Development and Reform Commission, "Collected Works on Energy Issues," China Environment Science Press, Beijing, 2009, p. 296.

[28] M. den Elzen, et al., "FAIR 2.0: A Decision-Support Tool to Assess the Environmental and Economic Consequences of Future Climate Regimes,” RIVM Report 2003, Netherland, 2003.

[29] J. H. Pan, "Fulfilling Basic Development Needs with Low Emissions-China's Challenges and Opportunities for Building a Post-2012 Climate Regime,” In: T. Sugiyama, Ed., Governing Climate: The Struggle for a Global Framework beyond Kyoto, International Institute for Sustainable Development, Tokyo, 2005, pp. 87-208.

[30] W. X. Wu, “On Environment Right-Public Law Perspective,” Law Press, Beijing, 2007, p. 127.

[31] The Project Group of International Human Rights Law Textbook, "International Human Rights Law Textbook,"
China Political and Law Press, Beijing, 2002, p. 464.

[32] R. Tol, "Estimates of the Damage Costs of Climate Change,” Environmental \& Resource Economics, Vol. 21, No. 2, 2002, pp. 135-160. doi:10.1023/A:1014539414591

[33] International Energy Agency, " $\mathrm{CO}_{2}$ Emissions from Fuel Combustion 1971-2004,” Organization for Economic, Paris, 2006.

[34] The United Nations Development Program, "Human Development Report 2007/2008,” The United Nations, 2007/ 2008, pp. 40-41.

[35] World Resources Institute's Climate Analysis Indicators Tool. http://cait.wri.org

[36] D. A. Farber, "Basic Compensation for Victims of Climate Change," University of Pennsylvania Law Review, Vol. 155, No. 4, 2007, p. 1605.

[37] B. A. Green, "Lessons from the Montreal Protocol: Guidance for the Next International Climate Change Agreement,” Environmental Law, Vol. 39, 2009, p. 279.

[38] The United States, "Expressing the Senses of the Senate Regarding the Conditions for the United States Becoming a Signatory to Any International Agreement on Greenhouse Gas Emissions Under the United Nations Framework Convention on Climate Change,” The 105th Congress, Washington DC, 1997.

[39] M. Weisslitz, "Rethinking the Equitable Principle of Common but Differentiated Responsibility: Differential versus Absolute Norms of Compliance and Contribution in the Global Climate Change Context," Colorado Journal of International Environmental Law \& Policy, Vol. 13, No. 2, 2002, p. 477. 